\title{
Direct Formation of a Polyimide Seamless Belt from Nylon Salt-type Monomer
}

\author{
Naoki Nishiura,,${ }^{1, \dagger}$ Tooru MuraKami, ${ }^{2}$ Kenzo OKAMoto,${ }^{3}$ and Masaru IshiKawa ${ }^{3}$ \\ ${ }^{1}$ Research and Development Center, Gunze Limited, 163 Morikawara-cho, Moriyama 524-8501, Japan \\ ${ }^{2}$ Research and Development Unit, Specialty Chemicals and Products Division, Ube Industries Limited, \\ 1978-10 Kogushi, Ube 755-8633, Japan \\ ${ }^{3}$ Department of Polymer Science and Engineering, Faculty of Engineering, Yamagata University, \\ 4-3-16 Jonan, Yonezawa 992-8510, Japan
}

(Received June 30, 2004; Accepted October 21, 2004; Published March 15, 2005)

\begin{abstract}
The direct preparation of polyimide belts from nylon salt-type monomer solution by rotational molding was examined in order to mold the polyimide belts efficiently. The polyimide seamless belts could be copolymerized directly from a mixed solution consisting of symmetric nylon salt-type monomer (Y) solution and an asymmetric nylon salt-type monomer $(\mathrm{X})$ solution by rotational molding. The reason is that the blend with the asymmetric nylon salt-type monomer $(\mathrm{X})$ prevented the formation of powder caused by the crystallization of the polyimide film. The polyimides were compared with those of the two-step synthetic method that went through polyamic acid (PAA) of high molecular weight both the chemical structure and mechanical properties of the polyimide belts derived from the nylon salt-type monomer were the same as those of the polyimide belts prepared from PAA, and had equivalent mechanical strength. The manufacture of the electroconductive polyimide belts was possible directly from the nylon salt-type monomer solution in which the carbon black (CB) was uniformly dispersed. The above method is thus proposed as a new forming technique for an intermediate transfer belt of polyimide. [DOI 10.1295/polymj.37.145]

KEY WORDS Polyimide Seamless Belt / Rotational Molding / Asymmetric 2,3,3',4'-Biphenyltetracarboxylic Dianhydride / Polyamic Acid / Nylon Salt-type Monomer / Mechanical Properties /
\end{abstract}

A polyimide seamless belt instead of a metal roll is used in OA equipment such as a copying machine and a laser printer, ${ }^{1}$ because of excellent heat-resistance and mechanical characteristics. It has been suggested that an intermediate transfer belt of polyimide with semi-conductivity, produced by the addition of carbon black (CB), is suited for practical use in a color laser printer. $^{2}$

Polyimide is insoluble in organic solvents because of the rigid structure of the molecular chain and does not melt even at the temperature over the melting point. Therefore, polyimide film is made by a special two-step synthetic method. In the first stage, polyamic acid (PAA) is derived from acid anhydride and diamine. Generally, forming of the film is carried out in this stage of PAA, ${ }^{3-5}$ because PAA is soluble in an organic solvent. Polyimide film is prepared by thermal imidization of PAA. The general equation is shown in Scheme 1. Volksen et al. ${ }^{6}$ reported that the mechanical properties (tensile strength, elongation, tensile elasticity) of a polyimide films depend on weight-average molecular weight of the precursor PAA. However, in the two-step synthetic method that goes through the stage of PAA of high molecular weight, enormous energy and time are spent in order to remove the large quantity of organic solvent, be- cause the solubility of PAA is about $20 \mathrm{wt} \%$ in an organic solvent. This becomes a disadvantage to manufacturing efficiency. It has been reported that the polyimide can be prepared from a nylon salt-type monomer solution. ${ }^{7,8}$ The general equation is shown in Scheme 2. In this case, the concentration of polyimide of about $45 \mathrm{wt} \%$ could be realized in the solution. The present authors prepared a symmetric nylon salt-type monomer (Y) solution with a solids concentration of $40 \mathrm{wt} \%$ from the diester of symmetric 3,3',4,4'biphenyltetracarboxylic dianhydride (s-BPDA) and 4,4'-oxydianiline (ODA). Preparation of a polyimide seamless belt directly from the nylon salt-type monomer solution was then attempted by rotational molding. However, the coating became a powder during heat treatment, and a polyimide belt could not be molded. The structure of the polyimide films derived from asymmetric $2,3,3^{\prime}, 4^{\prime}$-biphenyltetracarboxylic dianhydride (a-BPDA) and ODA are amorphous (noncrystalline structure). ${ }^{9}, 10$ Therefore, the crystallization during the imidization of the symmetric nylon salttype monomer ( $\mathrm{Y})$ is depressed using asymmetric nylon salt-type monomer $(\mathrm{X})$.

This study examines the forming the polyimide seamless belt from a mixed nylon salt-type monomer solution consisting of a symmetric nylon salt-type

${ }^{\dagger}$ To whom correspondence should be addressed (E-mail: naoki.nishiura@gunze.co.jp). 


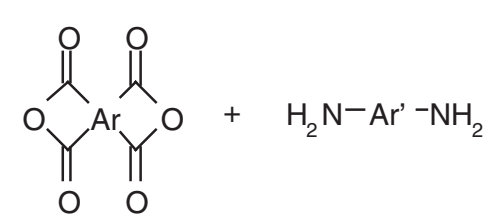

Acid Anhydride
Diamine<smiles>CCC(C)(C)NC(=O)[Te](C(=O)O)(C(=O)O)C(=O)N[Te]C</smiles>

Polyamic acid<smiles>CCC(C)(C)N1C(=O)[Te]2(C(=O)N([Al]C)C2=O)C1=O</smiles>

Polyimide

Scheme 1 .

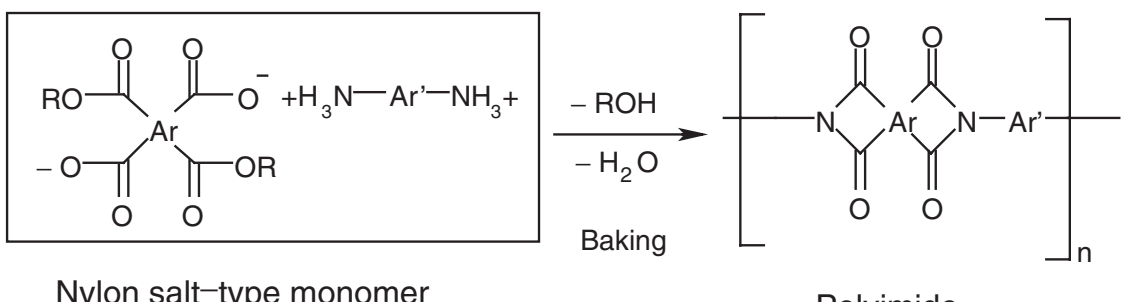

Nylon salt-type monomer

Polyimide

Scheme 2.

monomer (Y) solution and asymmetric nylon salt-type monomer $(\mathrm{X})$ solution by rotational molding. The polyimides are compared with those of the two-step synthetic method that went through PAA of high molecular weight. Electroconductive polyimide belts were produced from the nylon salt-type monomer solution in which $\mathrm{CB}$ was uniformly dispersed, and the electrical characteristics were evaluated.

\section{MATERIALS AND EXPERIMENTAL}

\section{Materials}

Nylon salt-type monomer (Y) solution was prepared according to Scheme 3. The aromatic tetracarboxylic acid diester was synthesized by mixing symmetric s-BPDA with methanol, and the nylon salttype monomer (Y) solution was prepared by adding an equimolar quantity of ODA powder to the aromatic tetracarboxylic acid diester dissolved in a mixed solvent with methanol and $N$-methyl-2-pyrrolidone (NMP) for $3 \mathrm{~h}$ at $50^{\circ} \mathrm{C}$ temperature under nitrogen. Excess methanol was evaporated for $1 \mathrm{~h}$ at $60^{\circ} \mathrm{C}$. Nylon salt-type monomer (X) solution was prepared from asymmetric a-BPDA according to Scheme 4. A mixture of the solutions of the nylon salt-type monomers was produced by blending at $\mathrm{X}: \mathrm{Y}=50: 50$ and $\mathrm{X}: \mathrm{Y}=20: 80$. The solid concentration was $38.0 \mathrm{wt} \%$ and viscosity was $0.3 \mathrm{~Pa}$ s. The solutions are represented as $\mathrm{XY}=50 / 50$ for mixing in the proportion of $\mathrm{X}: \mathrm{Y}=50: 50$ and as $\mathrm{XY}=20 / 80$ for mixing in the proportion of $\mathrm{X}: \mathrm{Y}=20: 80$.

Scheme 1 shows the process of imidization through the stage of PAA. PAA solution was prepared by adding an equimolar amount of dianhydride powder (s-BPDA:a-BPDA $=0.5 \mathrm{~mol}: 0.5 \mathrm{~mol}$, or s-BPDA: a-BPDA $=0.8 \mathrm{~mol}: 0.2 \mathrm{~mol})$ to NMP solution with ODA, $1.0 \mathrm{~mol}$. Solid concentration was $14.5 \mathrm{wt} \%$ and weight-average molecular weight was 32,000 by GPC. The solutions were represented as $\mathrm{PAA}=50 / 50$ for mixing in the proportion of s-BPDA:a-BPDA $=0.5$ mol:0.5 mol and as PAA $=20 / 80$ for mixing in the proportion of a-BPDA:s-BPDA $=0.2 \mathrm{~mol}: 0.8 \mathrm{~mol}$.

Acid carbon black was used with specific surface area of $180 \mathrm{~m}^{2} / \mathrm{g}$ and density of $1.85 \mathrm{~g} / \mathrm{cm}^{3}$. The diameter of the primary particles was $25 \mathrm{~nm}$, DBP oil absorption was $110 \mathrm{~mL} / 100 \mathrm{~g}$ (the test is standardized since 1965 as ASTM D2414) and the volatile component was $14.0 \%$. 


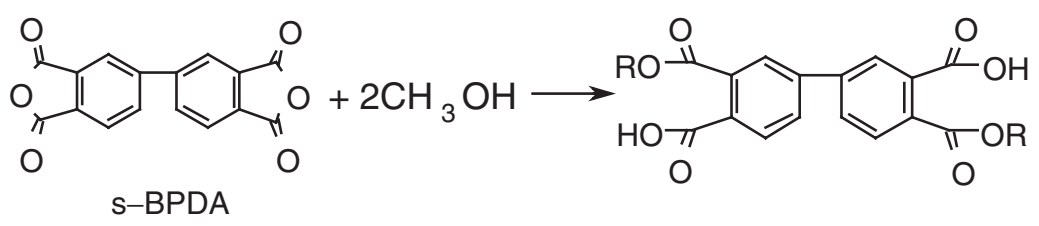<smiles>Nc1ccc(Oc2ccc(N)cc2)cc1</smiles>

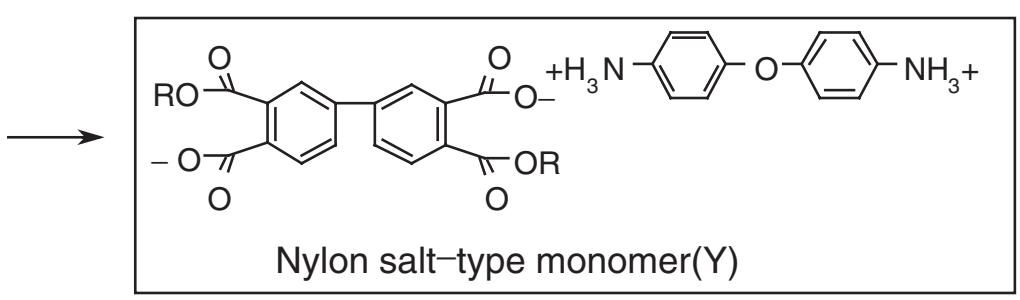

Scheme 3.<smiles>O=C(O)c1ccc(-c2cccc3c2C(=O)OC3=O)c(C(=O)O)c1</smiles><smiles>Nc1ccc(Oc2ccc(N)cc2)cc1</smiles><smiles>O=C(O)c1cccc(-c2cccc(C(=O)O)c2C(=O)O)c1</smiles>

Scheme 4.

Formation of Polyimide Belt by Rotational Molding

Figure 1 shows the forming the polyimide seamless belts by rotational molding. Cylinder mold inner diameter was $270 \mathrm{~mm}$ and length was $550 \mathrm{~mm}$.

1) $\mathrm{CB}$ dispersion: The addition of $\mathrm{CB}$ was adjusted in order to create a $\mathrm{CB}$ concentration of 14.0 wt $\%$ for the polyimide component of $\mathrm{XY}=$ $20 / 80$ and PAA $=20 / 80 . \mathrm{CB}$ was dispersed into by a sand mill method.
2) Casting and rotational molding: Molding solution was uniformly coated over a width of $500 \mathrm{~mm}$ on the inside of the cylinder mold rotated $100 \mathrm{rpm}$ (centrifugal: $15 \mathrm{~m} / \mathrm{s}^{2}$ ). Coated thickness to make the polyimide belt with a thickness of $100 \mu \mathrm{m}$ was calculated from the concentration of polyimide. Molding temperature was increased to $110^{\circ} \mathrm{C}$ for $80 \mathrm{~min}$ and hold for $70 \mathrm{~min}$. Temperature was increased again to $130^{\circ} \mathrm{C}$ for 


\section{Carbon black dispersion process}

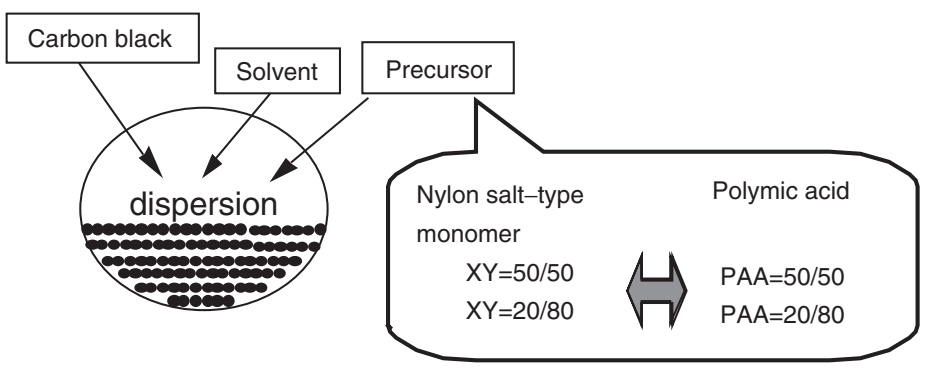

2. Casting and rotational molding process
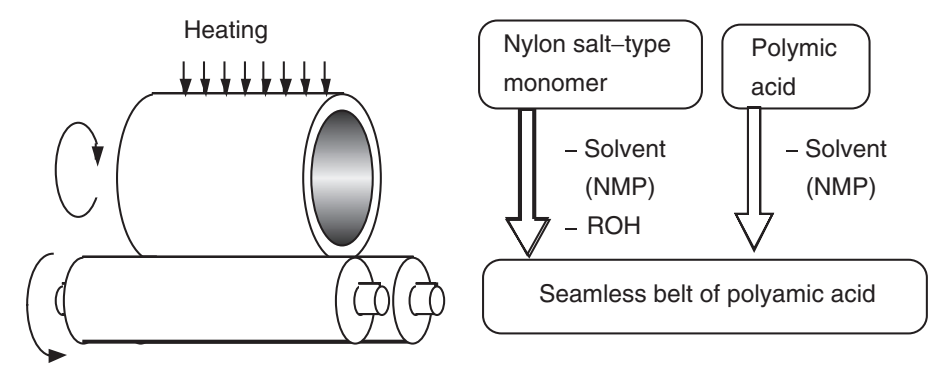

\section{Baking process}

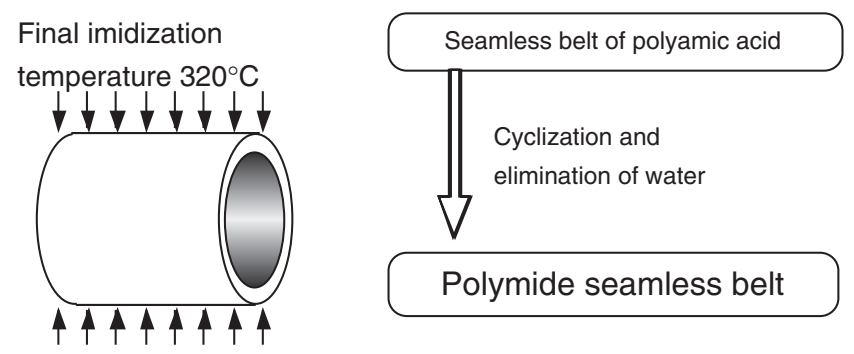

Figure 1. Forming of a polyimide seamless belt by rotational molding.

$30 \mathrm{~min}$. The concentration of solvent was reduced to one-half and the PAA belt was molded.

3) Baking: The forming of a seamless belt of polyimide was completed by dehydration imidization reaction of $\mathrm{PAA}$ at a high temperature of $320^{\circ} \mathrm{C}$ for $60 \mathrm{~min}$, while PAA belt adhered to the inside of the cylinder mold. The mold was cooled to room temperature and the seamless belt was taken out of the cylinder mold.

\section{Evaluation of Imidization and Properties of the Belt}

Evaluation of Imidization. Imidization was examined by dynamic viscosity $\left(\eta^{*}\right)$ of the solution measured on a SR-200 (Rheometric Scientific, Inc.) with a shear rate of $63.1 \mathrm{~s}^{-1}$ at a heating rate of $2{ }^{\circ} \mathrm{C} / \mathrm{min}$.

Characterization of Chemical Structure. The molecular structure of the seamless belt was examined by an infrared absorption spectrum (IR) measured by a Fourier transformation infrared spectroscope FT-IR 1600 type (PerkinElmer). Measurement was carried out by ATR. The dimensions of the test piece were $48 \mathrm{~mm}$ long and $13 \mathrm{~mm}$ wide.
Wide-angle X-ray diffraction (WAXS) was performed to examine crystallization of polyimide belt using a Rigaku RINT2500VHF (Cu, $200 \mathrm{~mA}, 45 \mathrm{kV})$ at room temperature with a sampling step of $0.02^{\circ}$ and scan rate of $1^{\circ} / 8.0 \mathrm{~s}$.

Evaluation of Mechanical Properties. Dynamic viscoelastic properties of the polyimde films were measured on a Rheometrics Solids Analyzer RSA (Rheometric Scientific, Inc.) at 60 to $400{ }^{\circ} \mathrm{C}$ and heating rate of $2^{\circ} \mathrm{C} / \mathrm{min}$. Frequency was $10 \mathrm{~Hz}$ and dynamic strain was $0.02 \%$. Test piece length was $27 \mathrm{~mm}$ and width $6 \mathrm{~mm}$. Frequency dependence was measured at $15.915-0.015915 \mathrm{~Hz}$ from $100{ }^{\circ} \mathrm{C}$ to near the glass transition temperature of $300^{\circ} \mathrm{C}$.

Mechanical properties such as Young's modulus, yield stress and tensile strength were measured on an Autograph AG-5KNe (Shimadzu Corp.). Crosshead speed was $200 \mathrm{~mm} / \mathrm{min}$, and gauge length was $40 \mathrm{~mm}$. The measurements of yield stress and tensile strength were carried out on a test piece of $5 \mathrm{~mm}$ width and $80 \mathrm{~mm}$ length. Young's modulus was measured on a test piece of $25 \mathrm{~mm}$ width and $250 \mathrm{~mm}$ 
gauge length; the crosshead speed was $25 \mathrm{~mm} / \mathrm{min}$ according to ASTM-D882.

Evaluation of Electrical Resistivity. Surface- and volume resistivity were measured using a Hiresta (Mistubishi Chemistry, Inc.). $100 \mathrm{~V}$ was applied and after $10 \mathrm{~s}$, resistivity was evaluated using a probe consisting of a main electrode of $1.6 \mathrm{~cm}$ diameter and a guard electrode of $3.0 \mathrm{~cm}$ inner diameter.

\section{RESULTS AND DISCUSSION}

\section{Preparation Technique of Polyimide Seamless Belts}

Figure 2 shows the relationship between mold temperature and concentration of volatilization gas during rotational molding for solutions of $\mathrm{XY}=50 / 50$ and $\mathrm{PAA}=50 / 50$. Volatilization gas concentration was measured by a contact burning-type gas sensor. Peaks of the volatilization gas from the $\mathrm{XY}=50 / 50$ solution appeared remarkably at 80 and $110^{\circ} \mathrm{C}$. Acid anhydride is formed by the elimination of alcohol. Subsequently, PAA was formed by reaction of the acid

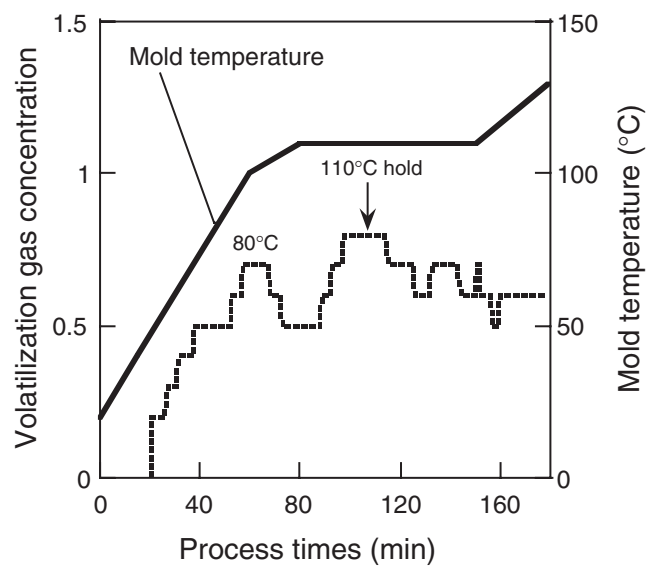

a) $\mathrm{XY}=\mathbf{5 0 / 5 0}$

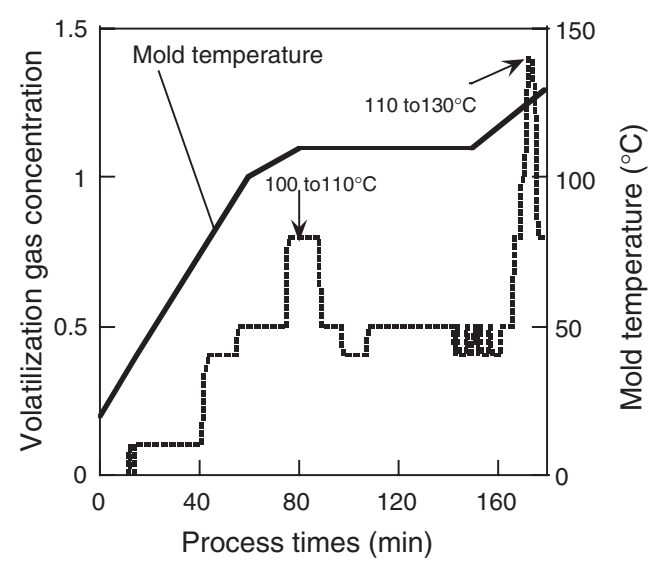

b) $\mathbf{P A A}=\mathbf{5 0 / 5 0}$

Figure 2. Relationship between mold temperature and volatilization gas concentration for $\mathrm{XY}=50 / 50$ and $\mathrm{PAA}=50 / 50$ solution during rotational molding. (a) $\mathrm{XY}=50 / 50$, (b) $\mathrm{PAA}=$ $50 / 50$. anhydride with the diamine. ${ }^{11,12}$ It was impossible to remove the film from the mold when the rotational molding was finished at a mold temperature of $130^{\circ} \mathrm{C}$. When the seamless belt, adhering to the mold, was cooled to about $60^{\circ} \mathrm{C}$, many cracks developed in the film. This indicates that the molecular weight of PAA created by desorbed alcohol is low. The peak of the volatilization gas of NMP from the PAA = $50 / 50$ solution appeared remarkably at the mold temperature of 100 to $110^{\circ} \mathrm{C}$. Volatilization of the residual NMP solvent was observed at a mold temperature of 110 to $130^{\circ} \mathrm{C}$. These results show that the solvent evaporation from the PAA $=50 / 50$ solution is slower than that from the $X Y=50 / 50$ solution, and it requires a higher temperature. The seamless belt derived from the PAA $=50 / 50$ solution had sufficient strength as a film when rotational molding was finished at mold temperature of $130^{\circ} \mathrm{C}$, and even if at $60^{\circ} \mathrm{C}$, it was possible to peel the film from the metal mold. This result indicates that the seamless belt derived from the PAA $=50 / 50$ solution is composed of a sufficiently high molecular weight polymer. ${ }^{13}$

Figure 3 shows the variation in dynamic viscosity $\left(\eta^{*}\right)$ with increasing temperature for the $\mathrm{XY}=50$ / 50 solution, $\mathrm{XY}=20 / 80$ solution and PAA $=20 / 80$ solution. Apparatus with a shielding cover to prevent evaporation of the solvent was used for the measurement. The dynamic viscosity coefficient decreased slowly with temperature in all solutions at first. When temperature rose, increase in the dynamic viscosity coefficient was found near the temperature of $140^{\circ} \mathrm{C}$, and remarkable increase appeared over $160^{\circ} \mathrm{C}$. It is presumed that the increase in this dynamic viscosity $\left(\eta^{*}\right)$ is caused by imidization reaction. From Figure 3 imidization is independent of the mixture ratio of nylon type salt monomer (X) to nylon

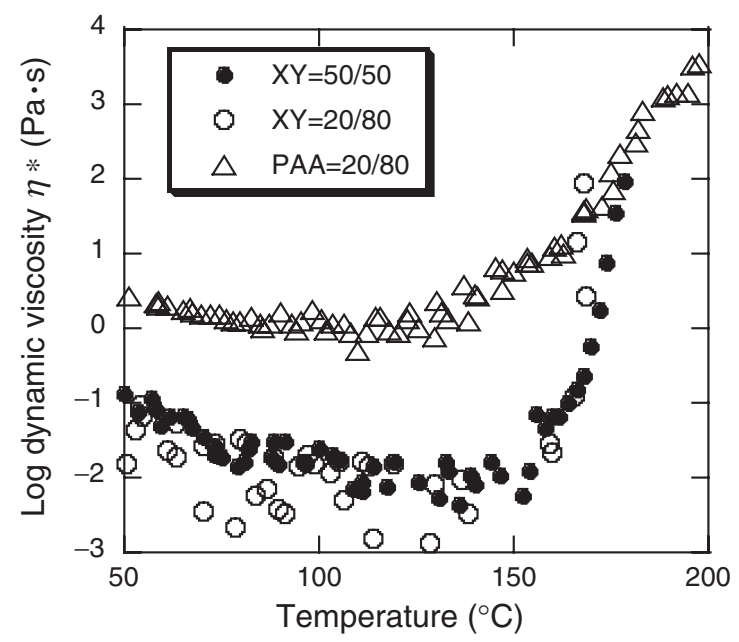

Figure 3. Variation in dynamic viscosity $\left(\eta^{*}\right)$ with increasing temperature for $\mathrm{XY}=50 / 50, \mathrm{XY}=20 / 80$, and $\mathrm{PAA}=20 / 80$ solutions. 


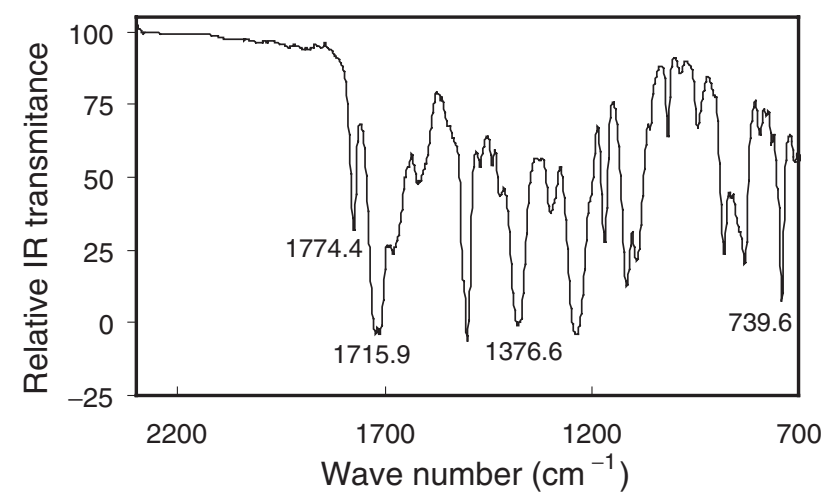

Figure 4. Infrared absorption spectrum of the film derived from $\mathrm{XY}=50 / 50$ solution at a mold temperature of $180^{\circ} \mathrm{C}$ by rotational molding.

type salt monomer $(\mathrm{Y})$. The reaction temperature of imidization is the same as that for the PAA $=20 / 80$ solution.

Figure 4 shows the IR spectra of the film derived from the $\mathrm{XY}=50 / 50$ solution at a mold temperature of $180^{\circ} \mathrm{C}$. There was no $\mathrm{NH}^{3+}$ absorption peak at 2140 , and $1610 \mathrm{~cm}^{-1}$ from the monomer derivation. Generation of the polyimide was confirmed from the absorption peak of the imide base near 1774.4, 1715.9, 1376.6, and $739.6 \mathrm{~cm}^{-1}$. Polyimide seamless belts can be produced by heating the nylon salt-type monomer at a temperature higher than $180^{\circ} \mathrm{C}$ in the interior of the cylinder mold. However, the unreacted component of imidization seems to greatly affect the characteristics of the polyimide. The polyimide belts were produced by heating the mixture of nylon salttype monomer solution at a temperature of $320^{\circ} \mathrm{C}$ in the interior of the cylinder mold to complete of imidization. Compositions of the polyimide belts are shown in Table I.

\section{Molecular Structure of Polyimide Seamless Belts}

Polyimide formed directly from the symmetric nylon salt-type monomer $(\mathrm{Y})$ solution becomes a powder. Structures of the polyimide films derived from a-BPDA and ODA are amorphous (noncrystalline structure). ${ }^{9,10}$ Therefore, crystallization due to the imidization of the symmetric nylon salt-type mono-

Table I. Properties of polyimide belts

\begin{tabular}{ccccc}
\hline \multirow{2}{*}{$\begin{array}{c}\text { Sample } \\
\text { no. }\end{array}$} & $\begin{array}{c}\text { CB content } \\
\text { (wt \%) }\end{array}$ & Precursor & \multicolumn{2}{c}{ Mole ratio of reactants } \\
\cline { 4 - 5 } & & a-BPDA & s-BPDA \\
\hline PI.1 & - & Salt monomer & 0.5 & 0.5 \\
PI.2 & - & Polyamic acid & 0.5 & 0.5 \\
PI.3 & - & Salt monomer & 0.2 & 0.8 \\
PI.4 & - & Polyamic acid & 0.2 & 0.8 \\
PI.5 & 14.0 & Salt monomer & 0.2 & 0.8 \\
PI.6 & 14.0 & Polyamic acid & 0.2 & 0.8 \\
\hline
\end{tabular}

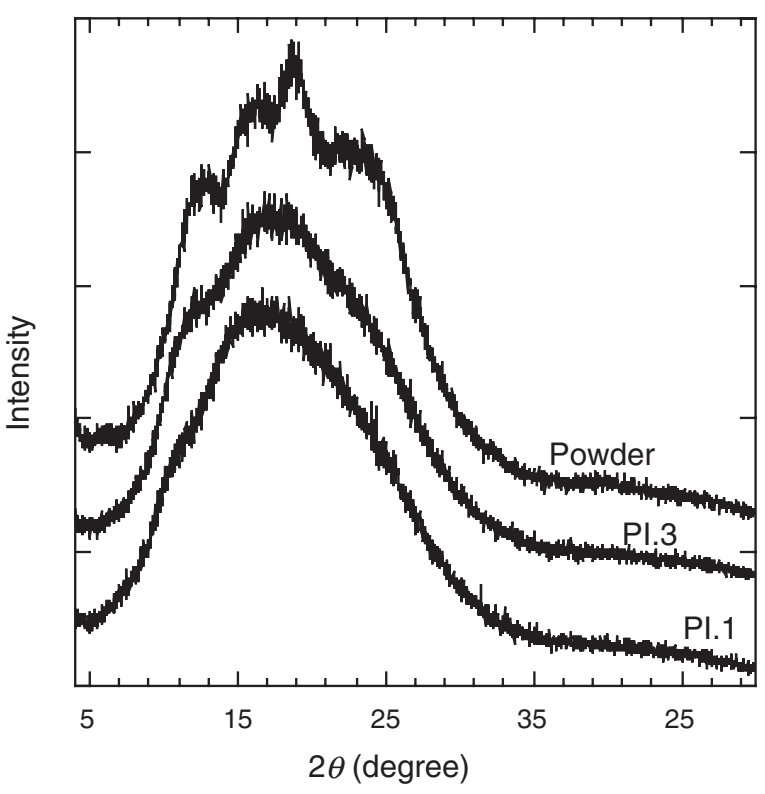

Figure 5. Reflection mode WAXD patterns of Powder, PI.1 and PI.3.

mer $(\mathrm{Y})$ is depressed by a mixture of the asymmetric nylon salt-type monomer $(\mathrm{X})$.

Figure 5 shows the reflection mode obtained by $\mathrm{X}$ ray diffraction for the powder of polyimide formed from the symmetric nylon salt-type monomer (Y) solution, PI.1 and PI.3. Peaks due to scattering from the crystalline phase were observed from the specimen of powder, and the pattern of reflection changed to a broad pattern due to the mixture with the asymmetric nylon salt-type monomer (X). Thus the blend with the asymmetric nylon salt-type monomer prevents the crystallization of the polyimide belt.

Figure 6 shows the IR spectra of PI.1-PI.4 polyimide belts derived from nylon salt-type monomer solution and PAA solution. IR spectra of PI.1 and PI. 2 produced from the solution of 50:50 blend ratios are shown as (a). IR spectra of PI.3 and PI.4 produced from the solution of 20:80 blend ratios are shown as (b). It was confirmed from the absorption peaks of the imide base near $1775,1716,1375,740 \mathrm{~cm}^{-1}$ that PI.1 and PI.3 were polyimide. The shapes of the spectrum of PI.1 and PI.3 were completely isomorphic with those of PI.2 and PI.4 derived from the PAA solution of high molecular weight. Chemical structures of these polyimide belts are thus identical.

\section{Mechanical Properties of Polyimide Seamless Belts}

Dynamic Viscoelasticity. The transverse direction (TD) represents the direction of the rotation of the polyimide belts (circumference, $848 \mathrm{~mm}$ ) and the machine direction (MD) represents the cross direction (width, $500 \mathrm{~mm}$ ). Dynamic viscoelasticity was measured in each direction. Figure 7 shows variation in 


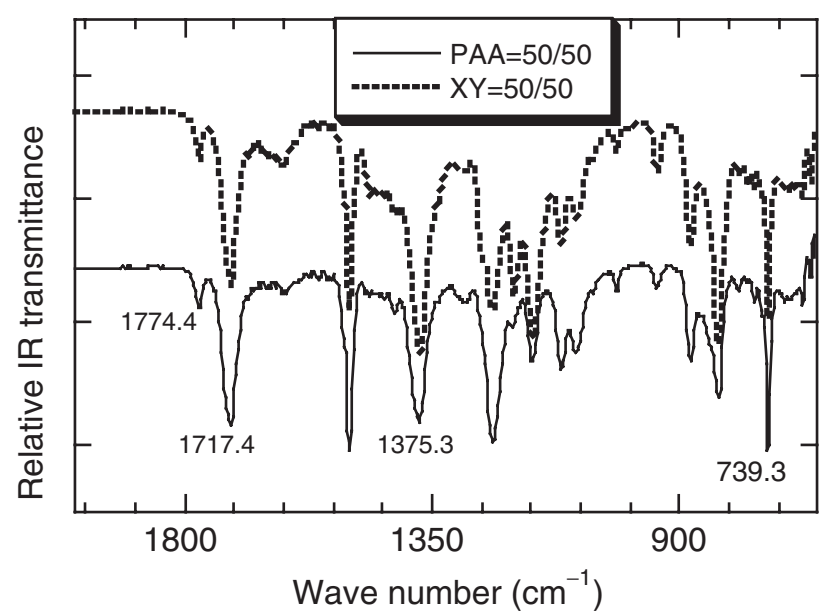

a) PI.1(XY=50/50) and PI.2(PAA=50/50)

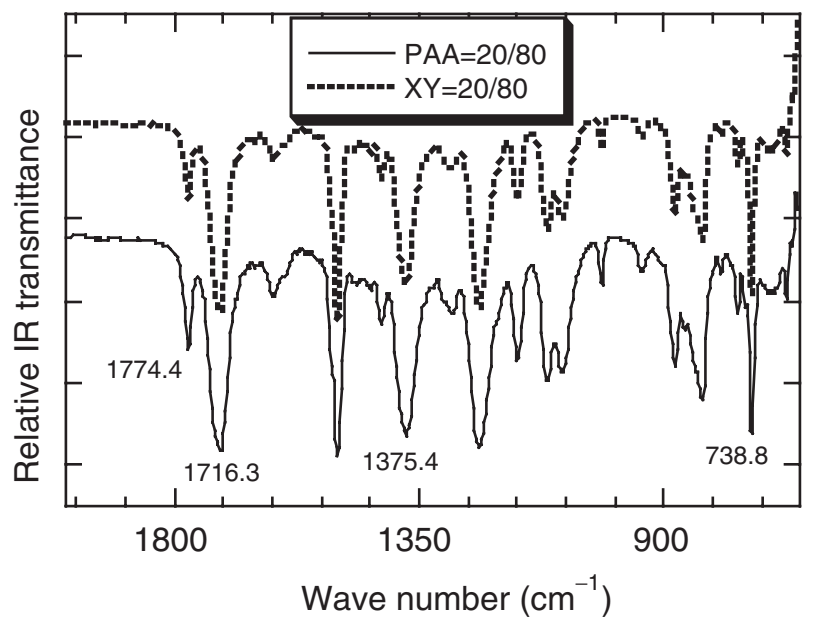

b) PI.3(XY=20/80) and PI.4(PAA=20/80)

Figure 6. Infrared absorption spectrum of various polyimide belts. (a) PI.1 (XY = 50/50) and PI.2 (PAA = 50/50), (b) PI.3 $(X Y=20 / 80)$ and PI.4 (PAA $=20 / 80)$.

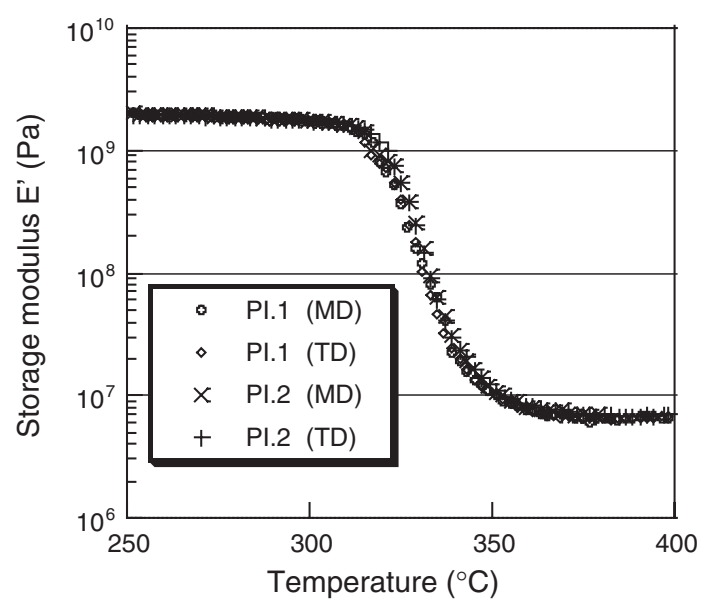

Figure 7. Variation in storage modulus $\left(E^{\prime}\right)$ for polyimide belts PI.1 and PI.2 with increasing temperature at a frequency of $10 \mathrm{~Hz}$. MD; Machine Direction, TD; Transverse Direction.

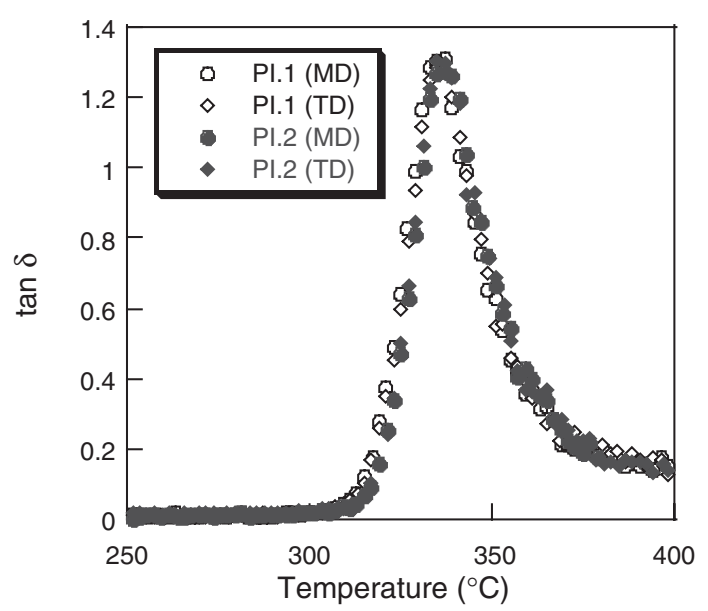

Figure 8. Variation in loss tangent $(\tan \delta)$ for polyimide belts PI.1 and PI.2 with increasing temperature at a frequency of $10 \mathrm{~Hz}$. $\mathrm{MD}$; machine direction, TD; transverse direction.

storage modulus $\left(E^{\prime}\right)$ for PI.1 and PI.2 with increasing temperature. There was no difference in storage modulus $\left(E^{\prime}\right)$ in each direction for PI.1 and PI.2. This result suggests that there is no anisotropy of the molecular orientation on a belt. Remarkable difference did not appear in the storage modulus $\left(E^{\prime}\right)$ of PI.1 and PI.2. It is thought that the higher order structure and molecular motion of PI.1 are same as for PI.2.

Figure 8 shows the temperature dependency of $\tan \delta$. A single peak of $\tan \delta$ was observed at temperature of $335^{\circ} \mathrm{C}$ for PI 1 and PI 2. The height of the peak of $\tan \delta$ is 1.3 in each belt, and the width and shape of the $\tan \delta$-temperature curve also are nearly identical. This indicates that the molecular weight distribution of PI.1 and PI.2 is independent of the method of imidization. Therefore, the manufacture of a polyimide belt with a high molecular weight is possible, even if the polyimide belts are molded directly from the nylon salt-type monomer.

Figures 9 and 10 show the frequency dependence of the storage modulus $\left(E^{\prime}\right)$ and the loss modulus $\left(E^{\prime \prime}\right)$ on PI.1 and PI.2, respectively. The measurement curves were superimposed at the reference temperature of $300^{\circ} \mathrm{C}$ using the transfer coefficient given in the WLF style, ${ }^{14}$ and is shown as superposition, synthesis curve. The storage modulus $\left(E^{\prime}\right)$ and loss modulus $\left(E^{\prime \prime}\right)$ in the rubber-like flat division were identical, and the shape of curve in the frequency range of the flat region was isomorphic. This result shows that the molecular weight between the entanglements of the polyamide belt derived from the nylon salt-type monomer solutions is the same as that from PAA of high molecular weight.

Tensile Strength. The weight-average molecular weight of PAA affects the structure and physical properties of the polyimide. Elongation of polyimide rap- 


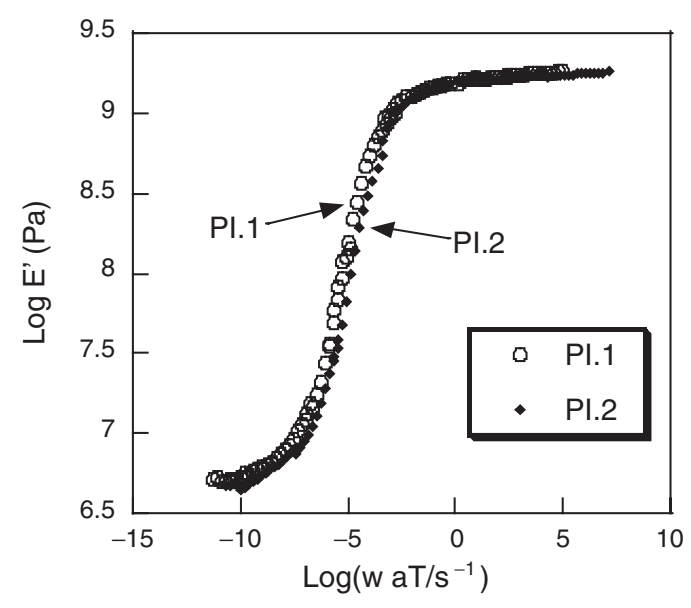

Figure 9. Frequency dependence of storage modulus $\left(E^{\prime}\right)$ at the reference temperature of $300^{\circ} \mathrm{C}$ for polyimide belts; PI.1 (TD) and PI.2 (TD).

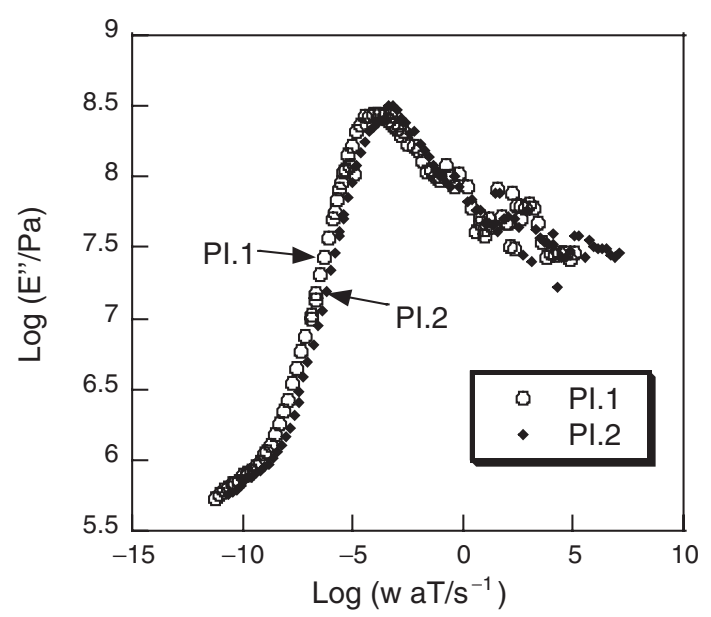

Figure 10. Frequency dependence of loss modulus $\left(E^{\prime \prime}\right)$ at the reference temperature of $300^{\circ} \mathrm{C}$ for polyimide belts; PI.1 (TD) and PI.2 (TD).

Table II. Mechanical properties of polyimide belts

\begin{tabular}{|c|c|c|c|c|}
\hline \multicolumn{5}{|l|}{ MD } \\
\hline $\begin{array}{l}\text { Sample } \\
\text { no. }\end{array}$ & $\begin{array}{l}\text { Yield stress } \\
\text { (MPa) }\end{array}$ & $\begin{array}{c}\text { Tensile strength } \\
(\mathrm{MPa})\end{array}$ & $\begin{array}{l}\text { Elongation } \\
(\%)\end{array}$ & $\begin{array}{l}\text { Young's modulus } \\
\text { (GPa) }\end{array}$ \\
\hline PI.1 & 136.2 & 161.5 & 83.5 & 3.35 \\
\hline PI. 2 & 135.6 & 162.8 & 79.5 & 3.34 \\
\hline PI.3 & 146.2 & 183.5 & 66.5 & 3.64 \\
\hline PI.4 & 147.5 & 182.0 & 67.5 & 3.65 \\
\hline \multicolumn{5}{|l|}{ TD } \\
\hline $\begin{array}{c}\text { Sample } \\
\text { no. }\end{array}$ & $\begin{array}{c}\text { Yield stress } \\
(\mathrm{MPa})\end{array}$ & $\begin{array}{c}\text { Tensile strength } \\
(\mathrm{MPa})\end{array}$ & $\begin{array}{c}\text { Elongation } \\
(\%)\end{array}$ & $\begin{array}{c}\text { Young's modulus } \\
\text { (GPa) }\end{array}$ \\
\hline PI.1 & 139.2 & 164.9 & 73.0 & 3.32 \\
\hline PI.2 & 139.9 & 165.2 & 73.5 & 3.37 \\
\hline PI.3 & 151.6 & 182.0 & 59.0 & 3.65 \\
\hline PI.4 & 150.3 & 182.7 & 60.0 & 3.61 \\
\hline
\end{tabular}

idly decreased with decrease in the weight-average molecular weight of less than $20,000 .^{6}$ The stress of the polyimide belt reached the yield stress at a tensile strain of 0.1 in the uniaxial tensile test, and plastic deformation occurred. Necking accompanying a drop in the nominal tensile stress occurred when the tensile strain was increased further. Table II shows yield stress, tensile strength, elongation to rupture and Young's modulus of the polyimide belt (PI.1-PI.4). Comparison with PI.1 and PI2 or PI.3 and PI.4 indicated no differences in mechanical properties. The above results show that the strength of the polyimide belt produced directly from the nylon salt-type monomer is equivalent to that produced by the two-step synthetic method that goes through PAA of high molecular weight.

\section{Electrical Characteristics of Polyimide Seamless Belts}

Table III shows the surface resistivity and volume
Table III. Electrical characteristics of polyimide belts

\begin{tabular}{cccc}
\hline $\begin{array}{c}\text { Sample } \\
\text { no. }\end{array}$ & $\begin{array}{c}\text { Surface resistance } \\
\text { Outside }(\Omega / \square)^{\mathrm{a}}\end{array}$ & $\begin{array}{c}\text { Surface resistance } \\
\text { Inside }(\Omega / \square)^{\mathrm{a}}\end{array}$ & $\begin{array}{c}\text { Volume resistance } \\
(\Omega \mathrm{cm})\end{array}$ \\
\hline PI.5 & $3.47 \times 10^{8}$ & $8.24 \times 10^{8}$ & $1.14 \times 10^{8}$ \\
PI.6 & $6.88 \times 10^{11}$ & $6.83 \times 10^{11}$ & $1.16 \times 10^{9}$ \\
\hline
\end{tabular}

${ }^{\mathrm{a}} \Omega / \square$ indicates the resistance per unit area.

resistivity for PI.5 and PI.6. Surface resistivity was measured outside and inside the belts. Both surface resistivity and volume resistivity of PI.5 derived from the nylon salt-type monomer were lower than those of PI.6 from PAA solution, even if the concentration of CB $(14.0 \mathrm{wt} \%)$ was the same. The electrical conductivity rapidly increased on dispersing $\mathrm{CB}$ in the nylon salt-type monomer. ${ }^{15}$ The surface resistivity outside the belt was equal to half that on the inside. This may be attributable to a gradient in the concentration of $\mathrm{CB}$ in the thickness direction. The disper- 
sion of $\mathrm{CB}$ particles in rotational molding is influenced by the centrifugal force. Because the viscosity of the $X Y=20 / 80$ solutions of the nylon salt-type monomer is low, CB particles move easily to the surface due to the centrifugal force.

The present results show that the manufacture of the electroconductive polyimide belts is possible directly from a nylon salt-type monomer solution in which $\mathrm{CB}$ was uniformly dispersed.

\section{CONCLUSIONS}

Imidization in a nylon salt-type monomer solution and the mechanical properties of polyimide belts prepared directly from this solution by rotational molding were examined, and the results were compared with those of polyimide belts prepared from PAA solution. The polyimides were then compared with those of the two-step synthetic method that went through PAA. Based on the results the following conclusions can be drawn:

1. Polyimide belts could be prepared from the mixture of a symmetric nylon salt-type monomer $(\mathrm{Y})$ with an asymmetric nylon salt-type monomer $(\mathrm{X})$, because the blend with the asymmetric nylon salt-type monomer prevents the crystallization of the polyimide belt.

2. The nylon salt-type monomer solutions of $X Y=$ $50 / 50$ and $X Y=20 / 80$ solutions offer the following advantages.

(a) Improvement in solubility (solutions containing $40 \%$ solids by weight are readily obtainable). (b) Low solution viscosity. (c) The solvent volatilization ends in a short time, and producibility is high.

3. Chemical structures and the mechanical properties of the polyimide belts derived from the nylon salt-type monomer were the same as those of the polyimide belts prepared from PAA of high molecular weight, and also that have equivalent mechanical strength.

4. The manufacture of the electroconductive polyimide belts is possible directly from a nylon salt-type monomer solution in which CB is uniformly dispersed. The above method is thus proposed as a new forming technique for an intermediate transfer belt of polyimide.

\section{REFERENCES}

1. T. Watanabe, H. Senba, and K. Kusaka, Electrophotography, 31, 156 (1992).

2. K. Ito, M. Goto, Y. Okuno, T. Yokoyama, Y. Fujimoto, and A. Nakajima, J. Imag. Soc. Jpn., 42, 109 (2003).

3. C. E. Sroog, A. L. Endrey, S. V. Abramo, C. E. Berr, W. M. Edwards, and K. L. Olivier, J. Polym. Sci., Part A: Polym. Chem., 3, 1373 (1965).

4. C. E. Sroog, J. Polym. Sci., Macromol. Rev., 11, 161 (1976).

5. C. E. Sroog, Prog. Polym. Sci., 16, 561 (1991).

6. W. Volksen, P. Cotts, and D. Yoon, J. Polym. Phys., 25, 2487 (1987).

7. T. T. Serafini, P. Delvigs, and G. R. Lightsey, J. Appl. Polym. Sci., 16, 905 (1972).

8. G. D. Roberts and R. W. Lauver, J. Appl. Polym. Sci., 33, 2893 (1987).

9. M. Hasegawa, N. Sensui, Y. Shindo, and R. Yokota, Macromolecules, 32, 387 (1999).

10. M. Hasegawa, N. Sensui, Y. Shindo, and R. Yokota, J. Polym. Sci., Part B: Polym. Phys., 37, 2499 (1999).

11. R. W. Lauver, J. Polym. Sci., Polym. Chem. Ed., 17, 2529 (1979).

12. G. D. Roberts and R. W. Lauver, J. Appl. Polym. Sci., 33, 2893 (1987).

13. C. C. Walker, J. Polym. Sci., Part A: Polym. Chem., 26, 1649 (1988).

14. M. L. Williams, R. F. Landel, and J. D. Ferry, J. Am. Chem. Soc., 77, 3701 (1955).

15. Y. Imai, T. Fueki, T. Inoue, and M. Kakimoto, J. Polym. Sci., Part A: Polym. Chem., 36, 1031 (1998). 